\title{
A nursing clinical data model for neuromuscular processes: content analysis of the Portuguese nursing customization
}

\author{
Um modelo clínico de dados de enfermagem em processos \\ neuromusculares: análise de conteúdo da parametrização \\ portuguesa
}

Hugo Neves (https://orcid.org/0000-0002-6843-6228) ${ }^{1}$

Paulo Parente (https://orcid.org/0000-0001-5396-9550) ${ }^{2}$

${ }^{1}$ Instituto de Ciências da Saúde, Universidade Católica Portuguesa. R. Diogo Botelho 1327. 4169-005 Porto Portugal. hugoneves@gmail.com

${ }^{2}$ Escola Superior de

Enfermagem do Porto.

Porto Portugal.

\begin{abstract}
This study targets the development of a nursing clinical data model for neuromuscular processes. To achieve this purpose, content analysis based on Bardin's perspective was performed on the Portuguese nursing local customizations regarding neuromuscular processes, with the International Classification for Nursing Practice concepts and the ISO 18104:2014 used as encoding rules. From analysis of the data, a total of 1766 diagnoses were related to neuromuscular processes. After application of exclusion criteria, a corpus with a total of 900 diagnoses was subjected to content analysis. After application of the encoding rules, a total of 81 context units were obtained, and through an inductive approach, were defined into three categories: clinical findings (e.g. aphasia); negative judgment diagnoses (e.g. impaired communication); transition properties (e.g. preparation and knowledge). These interpretations were validated by experts in the field. This study not only demonstrates the need to standardize data, but also the importance of neuromuscular processes in nursing practice. We hope this study will guide the definition of a nursing clinical data model that will help in increasing complexity in the level of care provided with high impact in the patient's quality of life.

Key words Nursing informatics, Nursing, Neurologic manifestations, Qualitative research
\end{abstract}

Resumo Este estudo tem como objetivo desenvolver um modelo clínico de dados de enfermagem para processos neuromusculares. Uma análise de conteúdo tendo por base a perspetiva de Bardin, foi realizada às parametrizações locais de Enfermagem em Portugal. O processo de codificação teve por base os conceitos da Classificação Internacional para a Prática de Enfermagem e a norma ISSO 18104:2014. Da análise inicial, 1766 diagnósticos encontravam-se relacionados com os processos neuromusculares. Após aplicação dos critérios de exclusão, um corpus de 900 diagnósticos foi sujeito à análise de conteúdo. Após o processo de codificação, 81 unidades de contexto foram obtidas e inseridas, através de processo indutivo, em três categorias: achados clínicos (ex: afasia); diagnósticos com juízo negativo (ex: comunicação comprometida); propriedades de transição (ex: preparação e conhecimento). Estas interpretações foram validadas por peritos na área. Este estudo permitiu evidenciar a importância dos processos neuromusculares, assim como a necessidade de uniformizar os dados. Pretende-se que este estudo oriente a definição de um modelo clínico de dados de Enfermagem que apoiará o aumento da complexidade dos cuidados de Enfermagem prestados, com alto impacto na qualidade de vida da pessoa. Palavras-chave Informática em enfermagem, Enfermagem, Manifestações neuromusculares, Pesquisa qualitativa 


\section{Introduction}

Nursing knowledge has seen a growth, particularly in the last decades. As a critical requirement for the assumption of Nursing as a science, this knowledge must be accompanied by a discipline-specific language ${ }^{1}$. Since its creation in 1996, the International Classification for Nursing Practice (ICNP) has been recognized by the World Health Organization (WHO) as a classification within the WHO-FIC, for the representation of nursing care ${ }^{2}$. Portugal was a pioneer in the introduction of this classification in the clinical context, revolutionizing, not only how practice was demonstrated in nursing records, but by using $\mathrm{ICNP}^{\circledR}$ as a strategy to introduce reflection of the nurses' autonomous field through the development of local customizations, with each context defining their core focus, diagnoses, interventions and indicators ${ }^{3}$.

Although this process resulted in an improvement of the nursing care, as this reflection opened horizons in terms of where nurses could intervene with higher impact in the person, the process was not centralized, leading to the development of multiple formulations of diagnoses and interventions with the same meaning, reducing interoperability ${ }^{3}$. Another problem that is arising is related to the rules to formulate diagnoses and interventions, which are currently different from the initial versions of ICNP, and follow the International Organization for Standardization $\left(\mathrm{ISO}^{\circledR}\right)$ standard 18104 for representation of nursing diagnoses and nursing actions in terminological systems $\mathrm{s}^{4,5}$.

To answer these two requirements, and to introduce formal knowledge optimizing decision-making through nursing informatics, the Nursing School of Porto (ESEP) have developed a project that aims to produce an ontology in nursing with direct application and implications in nursing practice. As part of this project, this study aims to address the content analysis of the neuromuscular processes found in the local customizations, to develop a nursing clinical data model (NCDM). In this article, we addressed the content analysis regarding nursing diagnoses that focused on issues related to neuromuscular disorders.

\section{Methodology}

To answer the research question "How do nurses diagnose the impact of neuromuscular process- es in the person", a descriptive study of qualitative nature was developed to perform a content analysis of the active local customizations as of 2013 from the public nursing information system (Sistema de Apoio à Prática de Enfermagem - $\left.\mathrm{SAPE}^{\circledR}\right)$, produced in community care and hospital units, as the first stage for the development of a NCDM for neuromuscular processes.

During the pre-analysis of the diagnoses, we selected diagnoses that evidenced problems related to neuromuscular disorders, such as signs and symptoms manifested by the individual. From the local customizations, a total of 1767 nursing diagnoses arose from this preliminary analysis. Afterward, assumptions and exclusion criteria were defined to select the corpus, and content analysis was performed according to Bardin's perspective.

According to Bardin ${ }^{6}$, categorical content analysis can be divided into the following steps:

1. Pre-analysis, consisting in the development of the corpus through the material selection;

2. Encoding, as the step of transforming the corpus raw data;

3. Categorization, where the corpus will be organized and classified based on criteria;

4. Interpretation, that evidences the inferential process.

The selection of Bardin's perspective is related to the fact that, to define a NCDM we need to demonstrate what are the nurses' concerns regarding the neuromuscular processes, but at the same time have a balanced standardized approach to increase interoperability, and this can only be obtained through the establishment of categories grounded on the data from the corpus, in this study ${ }^{6}$.

\section{Exclusion criteria}

To establish the corpus, we assumed specific exclusion criteria to filter the 1766 diagnoses subjected to analysis (Table 1). We considered blank diagnoses as all records that were left in blank, redundant diagnoses as all records that were poorly formulated and did not allow any ground for understanding the nurses' intention (e.g. "absent ability to execute active muscle-joint exercises"). Parent-related and caregiver-related diagnoses were also removed from the analysis, as it is the intention of this project to develop a NCDM that targets the individual's response and needs linked to neuromuscular processes. Self-care diagnoses were also removed as these are part of another ongoing thesis, while risk diagnoses were filtered 
Table 1. Exclusion criteria for establishment of corpus.

\begin{tabular}{lc}
\hline \multicolumn{1}{c}{ Criteria } & References \\
\hline Blank diagnoses & 7 \\
Redundant diagnoses & 27 \\
Parent-related diagnoses & 157 \\
Caregiver-related diagnoses & 8 \\
Self-care diagnoses & 3 \\
Risk diagnoses & 11 \\
Positive diagnoses & 653 \\
Total & 866 \\
\hline
\end{tabular}

because we understand that these reflect global problems and do not target the specific need of the person and focus of attention of the nurse. Positive diagnoses are related to the records that evidence a positive status that are related to the outcome rather than the diagnoses and are already reflected in other records with a negative status. A total of 866 records were removed from the initial data, resulting in the corpus with a total of 900 records.

\section{Analysis assumptions}

After the establishment of the corpus, some assumptions were made before proceeding with the encoding. These assumptions were discussed between the researcher and the expert involved in the project to increase interoperability, such as the level of granularity assumed that should have enough detail to evidence the nurses' intention, but not excessively granular to prevent comparability ${ }^{7}$. As such, no degree status was assumed (e.g. moderate dependence level), and all negative terms to express judgment (e.g. dependent, altered, ineffective) with the term "impaired" defined by ICNP ${ }^{\circledR}$ as "Negatively judged state, altered, impaired, or ineffective".

Another assumption was related to the individual's knowledge and abilities, with all diagnoses that were related to these concepts demonstrating the intention of the nurse to capacitate the individual, as well as recognizing that the person has the individual requirements for the nurse to intervene with this intention (e.g. motivation, volition).

\section{Encoding rules}

Assuming the categories will emerge from the data, the diagnoses subjected to analysis were encoded according to two main rules:
ICNP beta 2 focus and judgments used in the customization were updated to the ICNP concept definitions as of $2017^{8}$;

Category structure was based on the $\mathrm{ISO}^{\circledR}$ 18104:2014

Other rules used to encode the diagnoses included the introduction of terms that were considered as meaningful but were not available in ICNP ${ }^{\circledR}$ 's latest version. These new terms were identified between brackets [e.g. (antispastic) positioning technique].

After application of the encoding rules, the records were converted to context units that were later analyzed through the categorization process.

\section{Categorization}

An inductive approach was used, as categorization emerged and was grounded on the data. Nursing theories were considered to identify how nurses assessed neuromuscular processes and to understand the degree of depth in their approach to the person. This categorization was discussed between the main researcher and a total of three experts. Expert selection required an academic professional with experience in nursing informatics, nursing clinical data models and qualitative research.

\section{Ethical principles}

Data collected observed ethical requirements and are a result of the data extracted in 2014 by Serviços Partilhados do Ministério da Saúde (SPMS) and provided to ESEP. No individual record was accessed, and no identification variable was included in the database subjected to analysis.

\section{Interpretation and discussion of the results}

After encoding and categorizing the data, a total of 81 context units were obtained from the corpus, aggregated into 3 categories (Tables 2-4). From these categories, the most represented is "Transition properties", that account for $47,3 \%$ of the records analyzed with a total of 52 context units, followed by "Negative judgment diagnoses", with $35,3 \%$ encompassing 14 context units, and "Clinical findings" with 17,3\% representing 15 context units.

Categorization evidences the different levels of nursing practice, ranging from lower levels of 
Table 2. Content analysis of the corpus - Clinical Findings.

\begin{tabular}{llcc}
\hline Category & \multicolumn{1}{c}{ Context units } & Frequency & Percentage $^{*}$ \\
\hline \multirow{6}{*}{ Clinical } & Aphasia & 19 & 2,1 \\
& Expressive aphasia & 6 & 0,7 \\
& Impressive aphasia & 6 & 0,7 \\
& Agitation & 19 & 2,1 \\
& Confusion & 21 & 2,3 \\
& Slurred speech & 5 & 0,6 \\
& Autonomic dysreflexia & 4 & 0,4 \\
& Musculoskeletal pain & 1 & 0,1 \\
& Spasticity & 13 & 1,4 \\
& Stupor & 4 & 0,4 \\
& Paralysis & 11 & 1,2 \\
& Paresis & 18 & 2,0 \\
& Foot drop & 9 & 1,0 \\
& Joint contracture & 12 & 1,3 \\
& Somnolence & 8 & 0,9 \\
Subtotal & 15 & 156 & 17,3 \\
\hline
\end{tabular}

${ }^{*}$ Based on a total of 81 findings.

Table 3. Content analysis of the corpus - Negative judgment diagnoses.

\begin{tabular}{|c|c|c|c|}
\hline Category & Context units & Frequency & Percentage $^{\star}$ \\
\hline \multirow{14}{*}{$\begin{array}{l}\text { Negative } \\
\text { judgment } \\
\text { diagnoses }\end{array}$} & $\begin{array}{l}\text { Impaired active } \\
\text { range of motion }\end{array}$ & 19 & 2,1 \\
\hline & $\begin{array}{l}\text { Impaired } \\
\text { psychomotor } \\
\text { activity }\end{array}$ & 7 & 0,8 \\
\hline & $\begin{array}{l}\text { Impaired } \\
\text { cognition }\end{array}$ & 5 & 0,6 \\
\hline & $\begin{array}{l}\text { Impaired } \\
\text { communication }\end{array}$ & 59 & 6,6 \\
\hline & $\begin{array}{l}\text { Impaired } \\
\text { consciousness }\end{array}$ & 34 & 3,8 \\
\hline & $\begin{array}{l}\text { Impaired } \\
\text { swallowing }\end{array}$ & 65 & 7,2 \\
\hline & Impaired balance & 28 & 3,1 \\
\hline & $\begin{array}{l}\text { Impaired } \\
\text { chewing }\end{array}$ & 17 & 1,9 \\
\hline & $\begin{array}{l}\text { Impaired } \\
\text { memory }\end{array}$ & 12 & 1,3 \\
\hline & $\begin{array}{l}\text { Impaired short- } \\
\text { term memory }\end{array}$ & 8 & 0,9 \\
\hline & $\begin{array}{l}\text { Impaired long- } \\
\text { term memory }\end{array}$ & 8 & 0,9 \\
\hline & $\begin{array}{l}\text { Impaired body } \\
\text { movement }\end{array}$ & 22 & 2,4 \\
\hline & Impaired touch & 11 & 1,2 \\
\hline & Impaired vision & 23 & 2,6 \\
\hline Subtotal & 14 & 318 & 35,3 \\
\hline
\end{tabular}

${ }^{\star}$ Based on a total of 81 findings. complexity of nursing care (clinical findings), to higher levels of complexity (transition properties). This differentiation in nursing care may evidence the different levels of expertise from the nurses and how they can potentially influence nursing practice.

\section{Clinical Findings}

The category "Clinical findings" represent $17,3 \%$ of the records that were subjected to analysis. This category evidences the information that the nurses considered important for the development of interventions and that restricted the person's ability with impact in their quality of life and needs. Context units like "Paralysis" and "Paresis" affect the person's ability to perform certain activities and represent important data for the nurse specialist in rehabilitation that will help in the assessment and decision-making of the type of nursing interventions to be developed. This category also represents a lower level of depth when used as a diagnose by the nurse, as this data is related to clinical manifestations of neuromuscular disorders, which demonstrate a tendency of the nurse to focus on the physiological manifestations of a medical condition, rather than its impact on the person. This finding is similar to the study developed by Sousa et al. ${ }^{9}$ that evidence a model in use that approaches a biomedical view of the patient and the control of the disease and its manifestations. However, if used correctly and with a nursing model that moves away from this view, the findings observed in this category may be crucial for the development of a NCDM that uses this information, not as diagnoses, but rather as findings that can be introduced in the algorithm for the decision-making process. A good example of the importance of this data is, for example, the presence of "Confusion" or "Agitation", that will impair the person's ability to perform self-initiated activities and with impact in the range of available diagnoses related to the person's potential and needs (e.g. self-care related diagnoses).

Other context units, such as "Expressive aphasia" and "Impressive aphasia" may lead to a similar diagnose but with specific and different interventions and contribute for an individualization of care and higher quality nursing care, with optimal outcomes.

\section{Negative judgment diagnoses}

This category, representing $35,3 \%$ of the records and divided into 14 context units, is relat- 
Table 4. Content analysis of the corpus - Transition properties.

\begin{tabular}{|c|c|c|c|}
\hline Category & Context units & Freq. & Perc. ${ }^{\star}$ \\
\hline \multirow{52}{*}{$\begin{array}{l}\text { Transition } \\
\text { properties }\end{array}$} & Aphasia: Awareness & 1 & 0,1 \\
\hline & Potential to improve the ability to balance & 7 & 0,8 \\
\hline & Potential to improve the ability to perform (standing balance training technique) & 1 & 0,1 \\
\hline & Potential to improve the ability to perform (sitting balance training technique) & 1 & 0,1 \\
\hline & Potential to improve the ability to perform (balance training technique) & 6 & 0,7 \\
\hline & Potential to improve the ability to chew using (chewing technique) & 4 & 0,4 \\
\hline & Potential to improve the ability to communicate using communication device & 8 & 0,9 \\
\hline & Potential to improve the ability to perform active joint movement & 41 & 4,6 \\
\hline & Potential to improve the ability to perform feeding technique through gastric tube & 1 & 0,1 \\
\hline & Potential to improve the ability to perform swallowing technique & 18 & 2,0 \\
\hline & Potential to improve the ability to perform muscle or joint exercise technique & 59 & 6,6 \\
\hline & $\begin{array}{l}\text { Potential to improve the ability to perform muscle or joint exercise technique (of } \\
\text { the ankle joint) }\end{array}$ & 1 & 0,1 \\
\hline & Potential to improve the ability to perform positioning technique & 5 & 0,6 \\
\hline & Potential to improve the ability to perform positioning technique (antispastic) & 4 & 0,4 \\
\hline & Potential to improve the ability to perform positioning technique of foot drop & 1 & 0,1 \\
\hline & Potential to improve the ability to prevent spasticity & 1 & 0,1 \\
\hline & Potential to improve the ability to prevent foot drop using corrective device & 2 & 0,2 \\
\hline & Potential to improve the ability to prevent joint contracture & 4 & 0,4 \\
\hline & Potential to improve the ability to use (communication strategies) & 15 & 1,7 \\
\hline & Potential to improve the knowledge about (complications) & 2 & 0,2 \\
\hline & Potential to improve the knowledge about (diet) & 3 & 0,3 \\
\hline & Potential to improve the knowledge about communication (strategies) & 16 & 1,8 \\
\hline & Potential to improve the knowledge about fine motor function (exercises) & 1 & 0,1 \\
\hline & Potential to improve the knowledge about (prevention) of autonomic dysreflexia & 3 & 0,3 \\
\hline & Potential to improve the knowledge about (prevention) of spasticity & 1 & 0,1 \\
\hline & Potential to improve the knowledge about (prevention) of foot drop & 5 & 0,6 \\
\hline & Potential to improve the knowledge about (prevention) of joint contracture & 6 & 0,7 \\
\hline & Potential to improve the knowledge about (postural re-education using a mirror) & 1 & 0,1 \\
\hline & Potential to improve the knowledge about (chewing technique) & 3 & 0,3 \\
\hline & Potential to improve the knowledge about (balance training technique) & 4 & 0,4 \\
\hline & Potential to improve the knowledge about aphasia & 1 & 0,1 \\
\hline & Potential to improve the knowledge about communication device & 2 & 0,2 \\
\hline & Potential to improve the knowledge about corrective device (of foot drop) & 3 & 0,3 \\
\hline & Potential to improve the knowledge about autonomic dysreflexia & 1 & 0,1 \\
\hline & Potential to improve the knowledge about balance & 14 & 1,6 \\
\hline & Potential to improve the knowledge about spasticity & 2 & 0,2 \\
\hline & $\begin{array}{l}\text { Potential to improve the knowledge about adaptation techniques for sensory } \\
\text { deficit }\end{array}$ & 9 & 1,0 \\
\hline & Potential to improve the knowledge about chewing & 2 & 0,2 \\
\hline & Potential to improve the knowledge about safety precautions & 40 & 4,4 \\
\hline & Potential to improve the knowledge about active joint movement & 36 & 4,0 \\
\hline & Potential to improve the knowledge about paresis & 2 & 0,2 \\
\hline & Potential to improve the knowledge about food preparation & 1 & 0,1 \\
\hline & Potential to improve the knowledge about joint contracture & 1 & 0,1 \\
\hline & Potential to improve the knowledge about (proprioception exercise) technique & 1 & 0,1 \\
\hline & Potential to improve the knowledge about feeding technique through gastric tube & 3 & 0,3 \\
\hline & Potential to improve the knowledge about swallowing technique & 15 & 1,7 \\
\hline & Potential to improve the knowledge about distraction technique & 4 & 0,4 \\
\hline & Potential to improve the knowledge about muscle or joint exercise technique & 49 & 5,4 \\
\hline & Potential to improve the knowledge about positioning technique & 5 & 0,6 \\
\hline & Potential to improve the knowledge about (antispastic) positioning technique & 4 & 0,4 \\
\hline & Potential to improve the knowledge about relaxation technique & 4 & 0,4 \\
\hline & Potential to improve the knowledge about foot drop positioning technique & 2 & 0,2 \\
\hline Subtotal & 52 & 426 & 47,3 \\
\hline
\end{tabular}

${ }^{*}$ Based on a total of 81 findings. 
ed to the assumption of all negative judgments were to be encoded as "Impaired". This category represents a higher level of depth in terms of nursing practice, as these represent data sensitive to nursing-specific knowledge, as these are related to records that evidence functions that are altered as a consequence of a neuromuscular disorder and have the potential to revert or improve due to nursing interventions. Some of the records found in the data can be related to the context units found in the "Clinical findings". As an example, the context unit "Expressive aphasia" can lead to the presence of an "Impaired communication", with communication being the normal function affected by the lesion (expressive aphasia) and compromises the ability of the person to communicate. While nursing interventions cannot directly impact in the lesion of the Broca's area, they can answer the impairment in communication by developing strategies that will help the person to communicate despite the presence of aphasia, thus being sensitive to nursing interventions.

Other context units are related to interventions specific for nurses specialized in rehabilitation $^{10}$. A good example of these context units is the "Impaired active range of motion", that evidences the need to develop interventions that optimize the active range of motion and demand knowledge from other disciplines such as physiology, that is part of the knowledge and competencies of the nurse specialist in rehabilitation.

As we can observe, in spite of being sensitive to nursing care, most of the records included in this category still evidence a biomedical approach (e.g. , with the nurse as the focus/care provider rather than a partner with the person in the development of nursing care, and do not evidence the capacitation/development of abilities as the perceived model defines?.

\section{Transition properties}

This category is based on a higher level of depth regarding nursing care, where the nursing model used is based on Meleis' transition theory ${ }^{11}$, whose properties allow for a better understanding of the field of autonomous nursing care. Opposite to the previous categories, after encoding according to the assumptions reflected above, $47,3 \%$ of the records in the corpus reflected an intention by the nurse to include the person in the caring process, by focusing in the capacitation and optimization of the decision-making process of the person (e.g. "potential to improve knowledge", "awareness").

This is particularly important when the development of neuromuscular disorder that impacts neuromuscular processes, lead to a need of transition by the person due to a new health condition, that can only be obtained by the empowerment and engagement of the person in the process. While in the other categories, the existence of certain context units could influence the ability of the nurse to integrate the person in the care process, this category evidences how nurses recognize potential for the person to adapt to this new situation, engaging and capacitating them to improve their health status, by developing adequate patterns of response such as mastery ${ }^{11}$.

Although "Potential to improve" is not a term defined in $\mathrm{ICNP}^{\circledR}$, its use is related to the fact that the person needs knowledge, but also that he has volition, motivation, is cognitively capable to understand the information, and that the information provided will capacitate the person (e.g. a tetraplegic has no potential to improve the ability to perform muscle or joint exercise technique, despite having many of the requirements previously listed).

Another interesting characteristic of this category relates to the level of granularity observed in previous categories when compared to this one. Unlike the others, where we observed less detailed context units (e.g. "aphasia", "impaired communication"), in this category, we opted to increase detail. This option is related to the fact that nursing care has a higher level of impact in this dimension and approaches the requirements of a discipline-based practice as, not only follows a nursing theory but also because the care is clearly patient-centered and implies all the dimensions related to the person, such as their health project. This resulted in the codification into 52 context units, compared to 29 context units of the previous two categories.

Another interesting observation has to do with the inexistence of certain terms in the ICNP ${ }^{\circledR}$, which is only observed in this category and can be explained by this increase in the level of detail of the context units [e.g. "Potential to improve the knowledge about (antispastic) positioning technique"]. This decision may have implications as it may lead to the need to introduce these new terms in future updates of ICNP ${ }^{\circledR}$ but will potentially improve the NCDM that is intended to be developed, by allowing the development of indicators that evidence more accurately the specific role of nurses. 
Nursing informatics is clearly part of the nursing practice and has been a reality since the introduction of SAPE ${ }^{\circledR}$ in the late 1990's. However, the information systems' requirements have changed with current customizations not answering these requirements. The nursing national customization was a project that was performed in a very short period of time ${ }^{3}$, which lead to the development of new researches that readdressed the records that were subject to content analysis in 2014. In this study, as part of a project to use this data to serve as the basis for the creation of clinical data models that will allow the development of an ontology in nursing, we aimed to understand how nurses perceive and represent neuromuscular processes in the nursing care plans.

The option for the use of a qualitative methodology based on Bardin's approach with the stated encoding rules appears to be a less time-consuming strategy to address the purpose of this project, with the potential to be much more representative of the nurses in Portugal as all the records analyzed were built by local teams, which in total represent thousands of nurses involved in the development of the customizations, in which nurse specialist in rehabilitation and experienced and expert nurses in neuromuscular processes contributed to its definition.

Encoding rules, while apparently deviating from the typical content analysis, were selected to increase interoperability and the potential of the data analyzed to become diagnoses in the future NCDM.

Through analysis of the three categories that emerged (clinical findings, negative judgement diagnoses, transition properties), we observed different levels of complexity in nursing care which may provide direction to the development of a nursing ontology that can answer these findings and, at the same time, provide guidance for higher levels of complexity in nursing care, with high impact in the patient's quality of life.

\section{Study limitations}

Although more than one expert were consulted to validate content analysis, due to time limitations, the use of a focus group was not possible. Although there is a certain level of agreement regarding the establishment of these categories, this approach may lead to the definition of new insight into the records, enriching the content analysis.

Despite representing most of the local customizations developed in Portugal, some data could not be integrated into the analysis as, at the time of the extraction, nursing data was not centralized, with the existence of multiple information systems that do not communicate between them, preventing the inclusion of a broader and richer data.

\section{Implications in research}

This study will help provide guidance the development of future reviews that will introduce formal knowledge in the context units that arose from the encoding process. The development of these reviews will allow the mapping of knowledge and optimize the interventions that provide the best answer to the data involved in this NCDM.

\section{Implications in practice}

Interoperability is crucial for the development of a more evidence-based practice and for the standardization of the assessment of care, reducing geographical imprecisions while maintaining individualization of care.

Through the definition of the categories related to the neuromuscular processes, we hope to produce the basis of the clinical data model that will contribute for the development of a nursing ontology that will produce higher quality information and, above all, with impact in the nurses' critical and clinical decision-making, improving the quality and standard of care to the person.

From paper to electronic health records, nurses are part of a system that produces trillions of terabytes of data. As such, it is a social demand of the utmost importance to optimize the data we produce. As such, nursing information systems must incorporate this demand in its architecture, by ceasing to be a mere data collection system that will only occupy bytes and become more useful and meaningful for the person by being part of the decision-making process. The development of a nursing ontology is part of the change the future expects of us. 


\section{Collaborations}

Both authors contributed to the preparation of the manuscript.

\section{References}

1. Watson J. Clarifying the discipline of nursing as foundational to development of professional nursing. Texto \& Contexto - Enfermagem. 2017; 26(4).

2. Warren JJ, Coenen A. International Classification for Nursing Practice (ICNP): Most-frequently Asked Questions. JAMIA 1998; 5(4):335-336.

3. Paiva A, Cardoso A, Sequeira C, Morais EJ, Bastos F, Pereira F, Padilha JM, Cruz I, Oliveira MF, Brito MA, Silva MA, Machado N, Sousa P, Sousa P, Marques P. Análise da parametrização nacional do Sistema de Apoio à Prática de Enfermagem - SAPE. Porto: Escola Superior de Enfermagem do Porto; 2014.

4. Marin HdF, Peres HHC, Dal Sasso GTM. Análise da estrutura categorial da Norma ISO 18104 na documentação em Enfermagem. Acta Paulista de Enfermagem 2013; 26(3):299-306.

5. International Organization for Standardization (ISO). Health informatics - Categorial structures for representation of nursing diagnoses and nursing actions in terminological systems (ISO 18104:2014). Geneva: ISO; 2014.

6. Bardin L. L'analyse de contenu. Paris: Presses universitaires de France; 1977.

7. Weaver C, Delaney C, Weber P, Carr R. Nursing and Informatics for the 21st Century: An International Look at Practice, Education and EHR Trends. $2^{\text {nd }}$ ed. Boca Raton: CRC Press; 2016.

8. International Council of Nurses (ICN). ICNP Browser. Geneva: International Council of Nurses; 2017. [cited 2018 Jun 15]; Available from: http://www.icn.ch/whatwe-do/ICNP-Browser/.

9. Sousa MRMGC, Martins T, Pereira F. O refletir das práticas dos enfermeiros na abordagem à pessoa com doença crónica. Revista de Enfermagem Referência 2015; (6):55-63.

10. Portugal. Regulamento $n^{\circ} 125$, de 18 de fevereiro de 2011. Competências específicas do Enfermeiro Especialista em Enfermagem de Reabilitação. Diário da República 2011; 18 fev.

11. Meleis AI, Sawyer LM, Im E-O, Hilfinger Messias DK, Schumacher K. Experiencing Transitions: An Emerging Middle-Range Theory. ANS Adv Nurs Sci 2000; 23(1):12-28.

Artigo apresentado em 02/04/2018

Aprovado em 22/10/2018

Versão final apresentada em 19/02/2019 